www.jmscr.igmpublication.org

Index Copernicus Value: 79.54

ISSN (e)-2347-176x ISSN (p) 2455-0450

crossref DOI: https://dx.doi.org/10.18535/jmscr/v7i6.48

\title{
Analysis of association of tubal sterilization with abnormal menstrual bleeding: A Cohort Study
}

\author{
Authors \\ Lt Col Prashant Sharma, Col Sudhir Mansingh \\ Command Hospital
}

\begin{abstract}
Background: To control the burning issue of rising trend in global population, Family planning methods play a major role. Tubal sterilization which is a permanent method of family planning is one of the most popular contraceptive choices in the majority of developing countries. Tubal sterilization is the commonest method of family planning. Following the tubal sterilization procedure, there has been discussions' regarding the existence of the post-tubal-ligation syndrome for decades.

Methods: In this prospective cohort study, 50 women with Pomeroy type of tubal ligation as the study group and 50 women with no previous tubal ligation as the control group were recruited with the objective of assessing menstrual abnormalities.

Results: Menstrual abnormalities were not significantly different between the case and control groups ( $p$ $=0.8$ ). The abnormal uterine bleeding frequency differences in two different age groups (30-39 and 40-45 years old) were also statistically insignificant $(p=0.91)$.

Conclusion: Tubal sterilization does lead to menstrual irregularities.

Keywords: Tubal Ligation, Menorrhagia, Dysmenorrhea.
\end{abstract}

\section{Introduction}

Family planning practices are defined as "educational, comprehensive medical or social activities which enable individuals, including minors, to determine freely the number and spacing of their children and to select the means by which this may be achieved"(1). Tubal sterilization is the method of family planning most commonly used. It is performed at the request of women who have completed childbearing and desire an effective and irreversible form of birth control. About $30 \%$ of women with completed family planning choose tubal ligation as a method of contraception ${ }^{(2)}$.. This routine procedure is a very safe and highly effective method of permanently controlling fertility.

Tubal sterilization may be performed via laparoscopy, mini-laparotomy, or hysteroscopy ${ }^{(3)}$. All techniques of tubal ligation in widespread use have low risk of surgical complications. Apart from contraceptive benefits, there are some studies that show that tubal ligation procedures are associated with decreased risk of epithelial ovarian cancers as well as an observed reduced risk of pelvic inflammatory disease ${ }^{(4-8)}$. The term post tubal sterilization syndrome has been used to include abnormal menstrual bleeding, dysmenorrhea, premenstrual distress, hysterectomy and miscellaneous other conditions 
like need for recanalization, feeling of regret, and menopausal syndrome ${ }^{(9)}$. The syndrome is hypothesized to be caused by blood circulation problems in and around the fallopian tubes and ovaries, pressure on nerves and intrapelvic adhesion.

Questions regarding Post tubal sterilization syndrome arose initially when Williams and colleagues reported in 1951 that sterilized women had a higher than expected occurrence of menorrhagia and metrorrhagia. After that the existence of a post-tubal-ligation syndrome of menstrual abnormalities has been debated for decades ${ }^{(10)}$. Resolving the dispute about menstrual disorders after tubal sterilization is important for safeguarding women's health. Therefore, we compared the occurrence of menstrual disorders in women with and without tubal sterilization. In this study, the incidence of bleeding disorders among sterilized women was compared with nonsterilized female population of the same age group.

Because of the importance of this debate, we compared the occurrence of menstrual abnormalities in women with and without tubal ligation.

\section{Materials and Method}

This cohort study was conducted in a Secondary health care centre of urban India. After obtaining institutional Ethics Committee approval and written informed consent, a prospective cohort of 50 tubal sterilization acceptors and 50 non acceptors were randomly selected from women attending gynecological OPD.

All women were aged between 20-40 yrs and were followed up for a period of 12 months to compare menstrual diary data.

Ladies having previous history of menstrual disorders were excluded.

Monthly menstrual diary analysis was studied for
a) Frequent/prolonged Bleeding
b) Reduced/Infrequent Bleeding,
c) Acceptable/Normal Bleeding pattern,
d) Painful menses (dysmenorrhea) and,
e) Other menstrual problems.

Clinically significant bleeding pattern were judged as per latest ICMR guidelines. The criteria being:

a) Frequent/Prolonged bleeding : if the subject has either of the followingbleeding runs $>10$ days

b) Reduced/Infrequent bleeding : if the subject has none of the above but has either of the following- bleeding runs 0 1day; average episode length 35 days; total bleeding days $<5$ days.

c) Acceptable /Normal bleeding pattern: if the subject has none of the above.

Tubal Sterilization procedure followed included minilaparotomy and postpartum sterilization i.e. within 06 wks postpartum including TS done with caesarean. A menstrual diary was given to both sets of women and they were trained to chart the menstrual bleeding patterns and related conditions. The Information was collected using a structured validated interview schedule.

The collected data was analyzed by SPSS statistical software (version 23). Chi-square test, student $\mathrm{t}$ test and ANOVA were used for comparison. $\mathrm{P}$ value of 0.05 or less was considered as statistically significant.

\section{Results}

A total of 50 ladies were subjected to Tubal sterilization whereas 50 ladies were taken as control group.

1. Out of 50 ladies subjected to TS, 1 lady on follow-up presented with reduced/infrequent bleeding, 1 lady presented with prolonged bleeding, 3 ladies presented with dysmenorrhea and none presented with any other menstrual problem as per table -.1. 
Table 1: Menstrual pattern of ladies undergone TS with respect

\begin{tabular}{|l|cc|cc|}
\hline Parameter studied & \multicolumn{2}{|c|}{$\begin{array}{c}\text { Tubal sterilization } \\
\text { Group }\end{array}$} & Control group \\
\hline $\begin{array}{l}\text { Acceptable } \\
\text { menstrual pattern }\end{array}$ & 38 & $(76 \%)$ & 39 & $(78 \%)$ \\
\hline $\begin{array}{l}\text { Reduced/Infrequent } \\
\text { bleeding }\end{array}$ & 2 & $(04 \%)$ & 2 & $(04 \%)$ \\
\hline Prolonged bleeding & 2 & $(04 \%)$ & 2 & $(04 \%)$ \\
\hline Dysmenorrhoea & 8 & $(16 \%)$ & 7 & $(14 \%)$ \\
\hline $\begin{array}{l}\text { Other menstrual } \\
\text { problem }\end{array}$ & 0 & $(0 \%)$ & 0 & $(0 \%)$ \\
\hline Total & 50 & $(100 \%)$ & 50 & $(100 \%)$ \\
\hline
\end{tabular}

\section{To ladies selected as controls}

Incidence of reduced infrequent bleeding among subjects who underwent tubal sterilization and the control group was found to be $4 \%$, Similarly the Incidence of dysmenorrhoea among subjects who underwent tubal sterilization was found to be $16 \%$ whereas in control group it is seen $14 \%$. The relative risk (RR) was found to be 1.02 at $95 \%$ Confidence Interval $\{0.15,6.93\}, \mathrm{p}$ value $=0.9$. With an RR value of 1.02 , the observation that $95 \% \mathrm{CI}$ for RR includes 1 and $\mathrm{p}$ value $>0.05$, it is inferred that the association between Tubectomised individuals and Reduced/infrequent bleeding is not significant. There is no significant association between exposure of tubal sterilization and menstrual disorders in the present study.

\section{Discussion}

Post tubal sterilization syndrome, especially menstrual irregularities and dysmenorrhea are important complications and there are lots of controversies in regard to these complications. Most recent studies concluded that tubal sterilization does not cause menstrual irregularities. Shobeiri et al. concluded that tubal sterilization does not cause menstrual abnormalities and Fagundes et al. study showed that no changes in the menstrual pattern could be observed 6 months after tubal sterilization ${ }^{(2,7)}$. Peterson et al. study on 95 women who underwent tubal sterilization approved that there are no persistent changes in intermenstural bleeding or the length of the menstrual cycle but they have more decrease in the number of days with bleeding $^{(8)}$.

Mackenzie et al. demonstrated that $6 \%$ of patients after sterilization undergo hysterectomy or endometrial ablation because of abnormal uterine bleeding, but tubal sterilization is not a risk factor for hysterectomy because of abnormal uterine bleeding ${ }^{(10)}$. So, the result of this study is compatible with the mentioned study.

Alison Mall et al. demonstrated that previous tubal ligation is a risk factor for hysterectomy after an ablation and the incidence of pathologically confirmed post ablation tubal sterilization syndrome is $6 \%{ }^{(11)}$.

Huber et al. reported that laparoscopic approach should be chosen for female sterilization because the complication rate of minilaparotomy are more frequent than laparoscopic approach while Moore et al. reported a case of a delayed emergency department presentation of a major vascular injury after laparoscopic tubal ligation ${ }^{(12-14)}$.

In this study, all tubal sterilization were performed by minilaparotomy approach and abnormal uterine bleeding and dysmenorrheal was not significantly different between sterilized and unsterilized groups.

\section{References}

1. International Institute for Population Sciences (IIPS) and Macro International. National Family Health Survey (NFHS3). India, Mumbai. 2005-6;1:1-24.

2. Shobeiri MJ, Atashkhoii S. The risk of menstrual abnormalities after tubal sterilization: a case control study. BMC Womens Health 2005. May;5 (1):5.10. 1186/1472-6874-5-5.

3. Ludermir AB, Machado KM, Costa AM, Alves SV, Araújo TV. Tubal ligation regret and related risk factors: findings from a case-control study in Pernambuco State, Brazil. Cad Saude Publica 2009. Jun;25(6):1361-1368.

4. Ozerkan K, Aydin G, Koc I, Uncu Y, Uncu G. Menstrual pattern following 
tubal sterilization. Med Sci Monit 2010. Apr;16(4):CR197-CR201.

5. Malhotra N, Chanana C, Garg P. Poststerilization regrets in Indian women. Indian J Med Sci 2007. Apr;61(4):186-191

6. Padhye S, Karki C. Voluntary surgical contraception: a study on level of satisfaction.Nepal Med Coll J 2003. Jun;5(1):18-21.

7. Fagundes ML, Mendes MC, Patta MC, Rodrigues R, Berezowski AT, de Moura $\mathrm{MD}$, et al. Hormonal assessment of women submitted to tubal ligation. Contraception2005.Apr;71(4):309-314

8. Peterson HB, Jeng G, Folger SG, Hillis SA, Marchbanks PA, Wilcox LS, U.S. Collaborative Review of Sterilization Working Group The risk of menstrual abnormalities after tubal sterilization. $\mathrm{N}$ Engl J Med 2000. Dec;343(23):16811687.10.1056/NEJM200012073432303

9. Harlow BL, Missmer SA, Cramer DW, Barbieri RL, Barbieri RL. Does tubal sterilization influence the subsequent risk of menorrhagia or dysmenorrhea? Fertil Steril 2002. Apr;77(4):754-760.

10. MacKenzie IZ, Thompson W, Roseman F, Turner E, Guillebaud J. A prospective cohort study of menstrual symptoms and morbidity over 15 years following laparoscopic Filshie clip sterilisation. Maturitas 2010. Apr;65(4):372-377 Published online 27 Jan 2010.10.1016/j.maturitas.2010.01.005

11. Mall A, Shirk G, Van Voorhis BJ. Previous tubal ligation is a risk factor for hysterectomy after rollerball endometrial ablation. Obstet Gynecol 2002. Oct;100(4):659-664.

12. Huber AW, Mueller MD, Ghezzi F, Cromi A, Dreher E, Raio L. Tubal sterilization: complications of laparoscopy and minilaparotomy. Eur J Obstet Gynecol Reprod Biol2007.
Sep;134(1):105-109Published online 26 Jul 2006.

13. Moore CL, Vasquez NF, Lin H, Kaplan LJ. Major vascular injury after laparoscopic tubal ligation. J Emerg Med $2005 . \quad$ Jul;29(1):6771.10.1016/j.jemermed.2005.01.009

14. Moradan S, Gorbani R. Is Previous Tubal Ligation a Risk Factor for Hysterectomy because of Abnormal Uterine Bleeding? Oman Med J. 2012 Jul;27(4):326-8. 


\section{Appx 'A'}

\section{Questionnaire}

1. Name of Patient

2. Age

3. Parity

4. Last Child Birth

5. Menstrual History
(a) Regularity
(b) No. of days of bleeding
(c) Dysmenorrhea :
Yes / No
(d) No. of pads changed/day
(e) Passage of clots
Yes /No

6. Surgical / Medical History

\section{Appx 'B'}

Menstrual Diary

\begin{tabular}{|c|c|c|c|c|c|c|c|c|c|}
\hline Month & Dysmenhor & & Period c & clicity & Bleeding & lays & Clots & & \\
\hline & $\begin{array}{l}\text { Yes } \\
\text { 1)Increase } \\
\text { 2)Decrease } \\
\text { 3)Same }\end{array}$ & No & $\begin{array}{l}\text { Altered } \\
1)>10 \\
\text { days } \\
2)<10 \\
\text { days }\end{array}$ & $\begin{array}{l}\text { Not } \\
\text { altered }\end{array}$ & $\begin{array}{l}\text { Increase } \\
>7 \text { days }\end{array}$ & $\begin{array}{l}\text { Decrease } \\
<2 \text { days }\end{array}$ & $\begin{array}{l}\text { New } \\
\text { appearance }\end{array}$ & $\begin{array}{l}\text { Increase } \\
\text { Yes/No }\end{array}$ & $\begin{array}{l}\text { Decrease } \\
\text { Yes/No }\end{array}$ \\
\hline 1st Month & & & & & & & & & \\
\hline $2^{\text {nd }}$ Month & & & & & & & & & \\
\hline $3^{\text {rd }}$ Month & & & & & & & & & \\
\hline $4^{\text {th }}$ Month & & & & & & & & & \\
\hline $5^{\text {th }}$ Month & & & & & & & & & \\
\hline $6^{\text {th }}$ Month & & & & & & & & & \\
\hline $7^{\text {th }}$ Month & & & & & & & & & \\
\hline $8^{\text {th }}$ MOnth & & & & & & & & & \\
\hline $9^{\text {th }}$ Month & & & & & & & & & \\
\hline $10^{\text {th }}$ Month & & & & & & & & & \\
\hline $11^{\text {th }}$ Month & & & & & & & & & \\
\hline $12^{\text {th }}$ Month & & & & & & & & & \\
\hline
\end{tabular}

